\title{
Design of coarse tailings and dry ash disposal facilities
}

\author{
AM Copeland Knight Piésold Consulting (Pty) Ltd, South Africa \\ JM Teixeira Knight Piésold Consulting (Pty) Ltd, South Africa
}

\begin{abstract}
The diamond industry has been disposing of its coarse tailings using conveyor and stacker systems for many years. The process plant typically generates two tailings products, a grit fraction (sand) and a coarse fraction (gravel), which are often combined on one dump. In some cases, the dump is stable with a single steep slope angle. However, in other situations a composite slope forms with settlement and intermittent slumping behaviour, this impacts on both design and operation.

The thermal coal industry has also been disposing of dry ash for many years using either conveyor/stacking systems or haul trucks. Both systems work well, but the costs, deposition plans and stability aspects differ. Management of water and dust are also key factors.

There are a number of key design and operational aspects that are similar between these diamond tailings and ash facilities, and would apply equally to filtered and dry stacked tailings. This paper aims to examine these similarities and show how these learnings could be built into new filtered tailings designs and operations to make them more efficient and stable.
\end{abstract}

Keywords: coarse tailings, ash, dry stacking, conveying, trucking

\section{Introduction}

The diamond mining and processing industry typically produces two residue products known as tailings and slimes. The tailings are a coarse material often defined by particles $>300$ microns and can range up to $25 \mathrm{~mm}$ in size. In some process plants fine tailings, known as grits, is produced and is often defined by particles $>300$ microns and $<1.6 \mathrm{~mm}$. The upper size depends on the diamond cut-off that the operation may choose to reject or to dispose of separately as a low-grade stockpile. The residue products are disposed of separately, with the tailings sent to a dump by conveyor, and the slimes pumped to a dam as a slurry. Depending on the kimberlite and process plant, the grits may be disposed with the slimes or tailings, or on its own dump. This paper will focus on the design and operation of the tailings dump, or dry stack (with and without the grits/fine tailings fraction).

The thermal coal industry produces bottom ash and fly ash which are usually co-disposed onto one facility. The fly ash is a predominantly silt-sized material which typically makes up $80 \%$ of the waste produced, the remaining material; the bottom ash is normally a sand size. In some cases, the ash is hydraulically disposed into dams, while for others it is kept dry and conveyed or trucked to a dump. This paper will focus on the dry disposal of ash and will consider cases of conveying versus trucking to a stack.

The purpose of the paper is to highlight similarities between these existing designs and operations, with potential new designs for fine tailings facilities such as gold, platinum or iron ore, which have been dewatered by means of filtration in the plant. It should be possible to make use of some of the learnings and experiences.

The paper is structured to cover diamond tailings cases first, then ash disposal, and concluding with similarities in the design and operation of future dry stack tailings facilities. 


\section{Diamond tailings}

\subsection{Tailings properties}

Most diamond tailings originate from kimberlite ore, however alluvial diamond mining also produces a fine slimes and coarse tailings that are separately disposed. Kimberlite tailings are susceptible to variable degrees of weathering depending on the smectite content, which contributes to the generation of clays within the tailings over time. These clays can alter the dump behaviour. For the purposes of dump design and material transportation, the tailings properties are governed by their initial grading of sands and gravels.

In the process plant, the grits and coarse tailings pass over dewatering screens before being dropped onto conveyors. The grits moisture content is often between 18 and $22 \%$ (metallurgical moisture content = mass of water/total mass). The coarse tailings moisture content will range from $6 \%$ for a gravel with a cutoff size of $25 \mathrm{~mm}$, up to $12 \%$ for a cutoff size of $10 \mathrm{~mm}$. The combined moisture content of grits plus coarse tailings ranges from 12 to $18 \%$ depending on the ratio of the two products.

The grits are typically 25 to $35 \%$ by mass of the total head feed, and 40 to $50 \%$ of the total tailings mass.

Laboratory testing of the grits and tailings shows that it behaves as a fully frictional material with friction angles of $30-33^{\circ}$ with zero cohesion. As mentioned, in practice, some inter-particle bonding occurs due to the release of clays by weathering, and their attraction of moisture. The tailings are relatively free draining, with high permeabilities, but again somewhat retarded by the presence of surface clay particles. Such a material would not be expected to develop a water table or pore pressures; however, this is possible under certain circumstances (deposition at high moisture contents and heavy rainfall).

The tailings typically consolidate to dry densities of between 1.55 and $1.60 \mathrm{t} / \mathrm{m}^{3}$, depending on the grading and the dump height.

\subsection{Key design aspects}

\subsubsection{Geotechnical and tailings test work}

A basic geotechnical investigation to determine foundation conditions of the dump site is required for design. Laboratory testing of the tailings is also essential, and where grits is added, it should cover a range of tailings such as grits ratios and moisture contents for determining in situ densities, slope angles, permeabilities and shear strengths. Obtaining representative samples for a new mine may be difficult and knowing what ratios will be produced and to test, may require testing to cover a wider range.

The conveyor designers will require tailings and grits samples to assess material handling characteristic at the chutes and transfer towers. The conveyors also have a limited slope at which they can operate without rollback due to these characteristics. This limitation is important for the design of the final dump.

\subsubsection{Dump slope angle}

The tailings dump slope angle is the next factor to consider. Since the tailings is either deposited over the edge of the dump by the spreader, or dozed over the edge, it typically flows down the side with some initial build-up prior to each slide or slough. It does not act like a loose dry sand, as the moisture in the tailings generates matric suction between the particles which causes some hang-up prior to each slump or flow. Over time the tailings consolidate and settle under their own weight. In many cases the upper slope will correspond to the angle of repose, but the lower slope depends on the grits and moisture contents. For coarse tailings only, a single slope develops such as Figure 1, but for a combined dump, it is common for a composite slope to develop. The composite slope may comprise a bulge similar to a potbelly shape as presented in Figure 2 and 3, or a concave shape flattening to a shallow angle near the toe as presented in Figure 4, but often with a nose at the toe, rather than a tapered shape. 


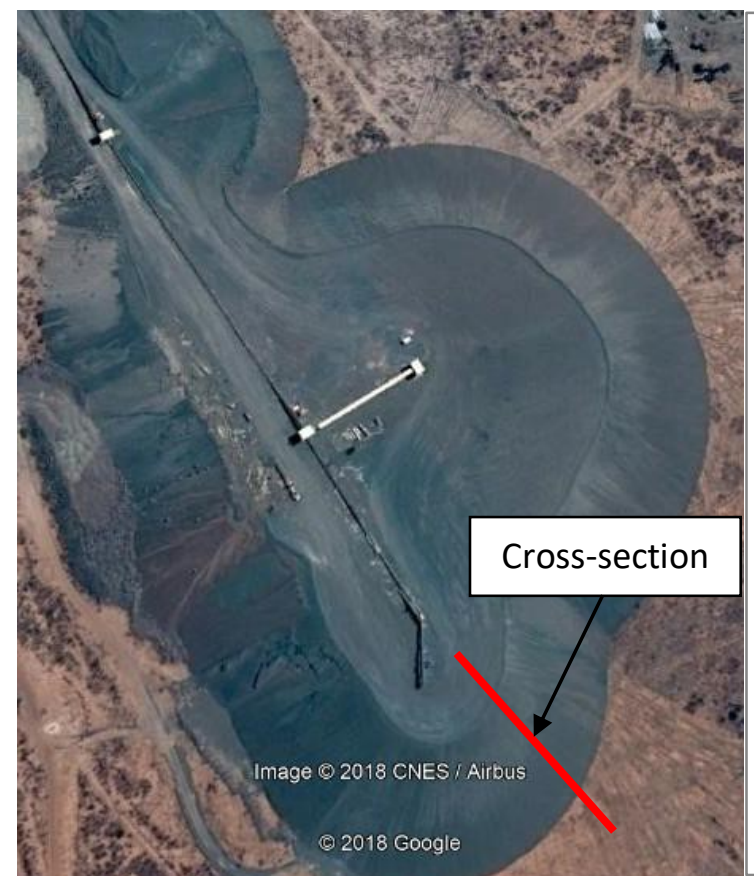

\section{Single Slope Cross Section}

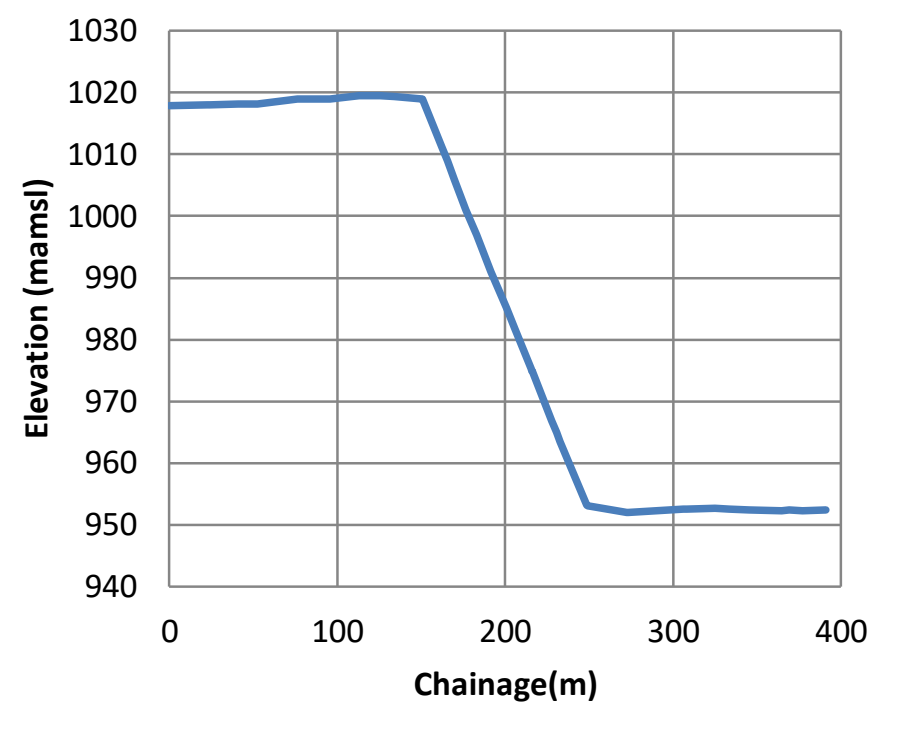

Figure 1 Google Earth image of single steep faced dump showing dozing and a new node/leg with appended typical cross-section
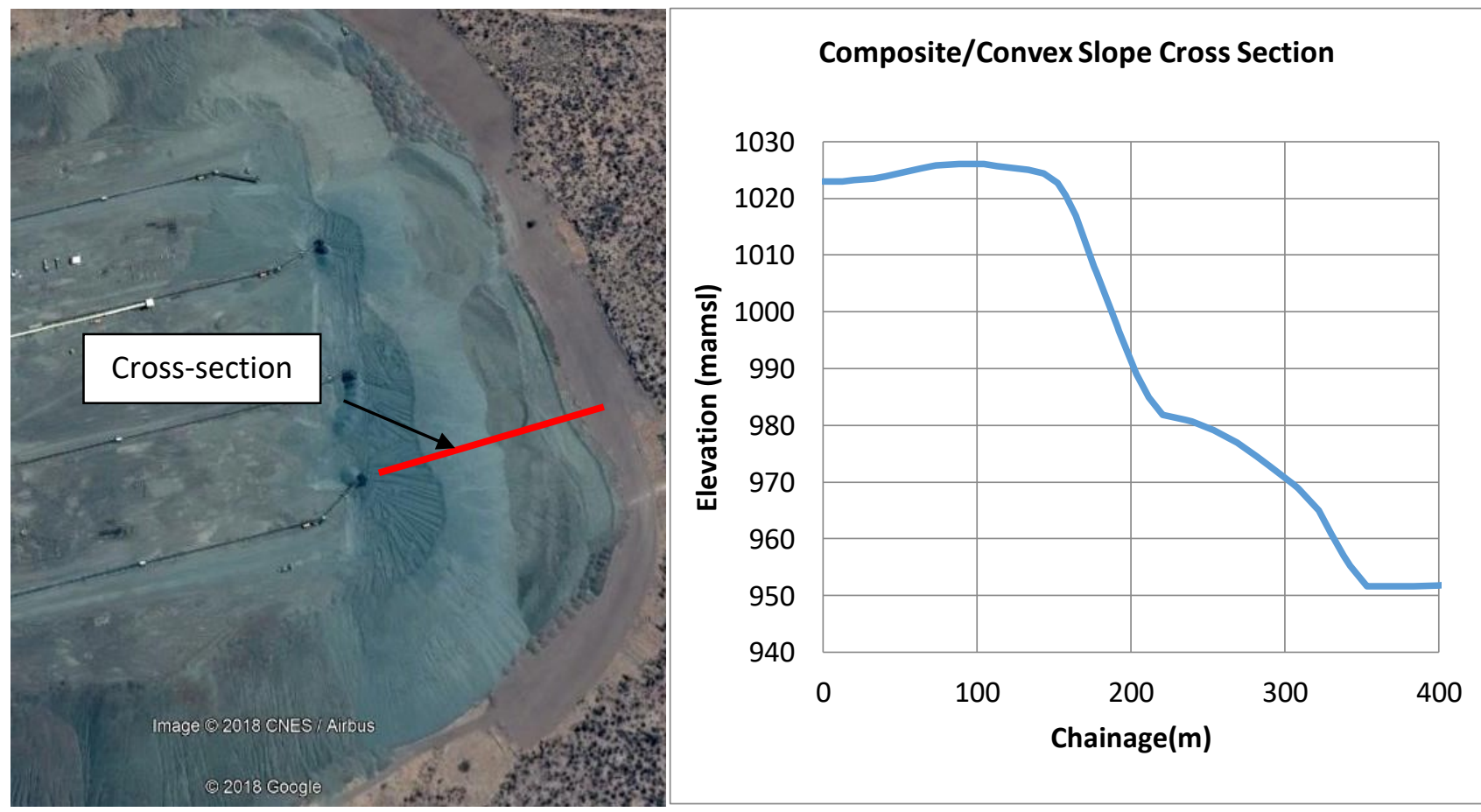

Figure 2 Google Earth image of a tailings dump that has slumped (bulge) with appended cross-section 


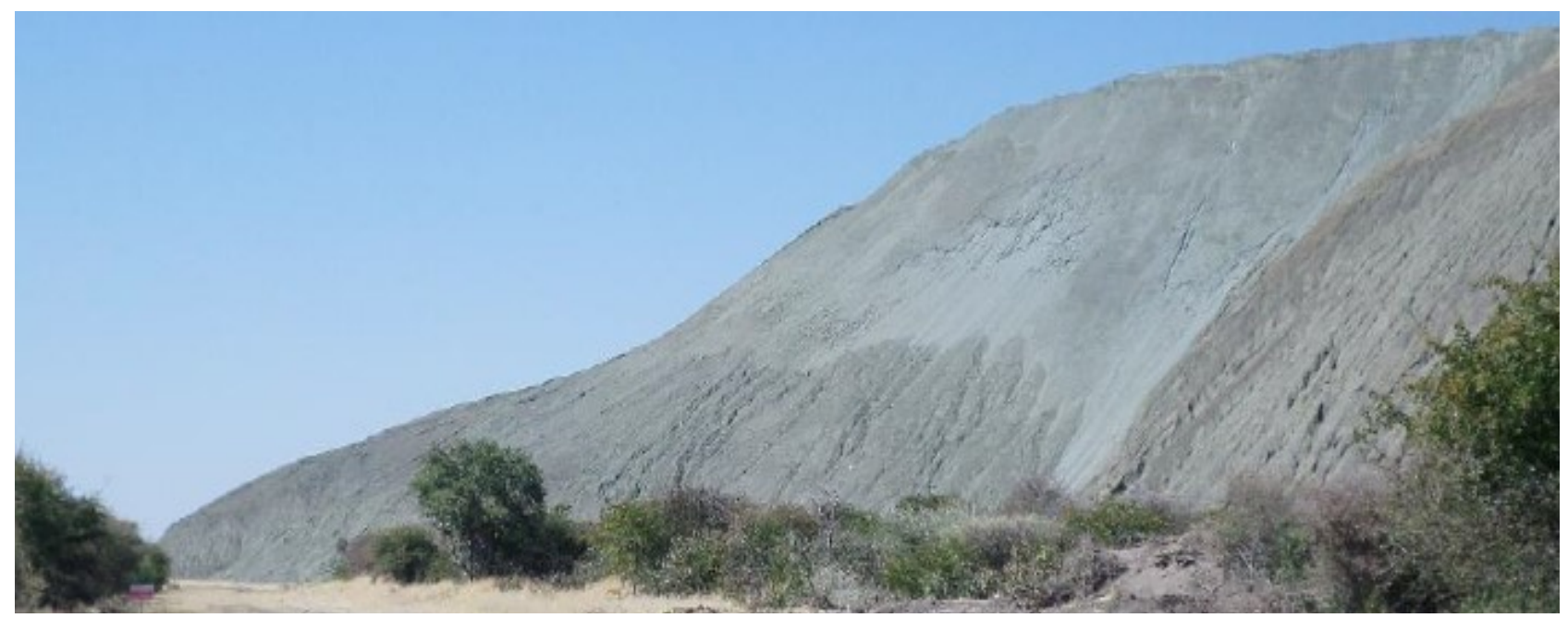

Figure 3 Photograph of a tailings dump that has slumped (bulge and nose)

The most unsafe dump is one where a single steep slope forms initially and then due to variations in grading or moisture contents a composite slope forms, followed by a reversal of the properties so that a steep slope forms again and starts advancing over a slumped bulge/toe. Such a dump has the potential to suddenly fail due to the weaker material near the base.

Figure 3 is a photograph of the composite/convex slope, which developed on the tailings dump in Figure 2.

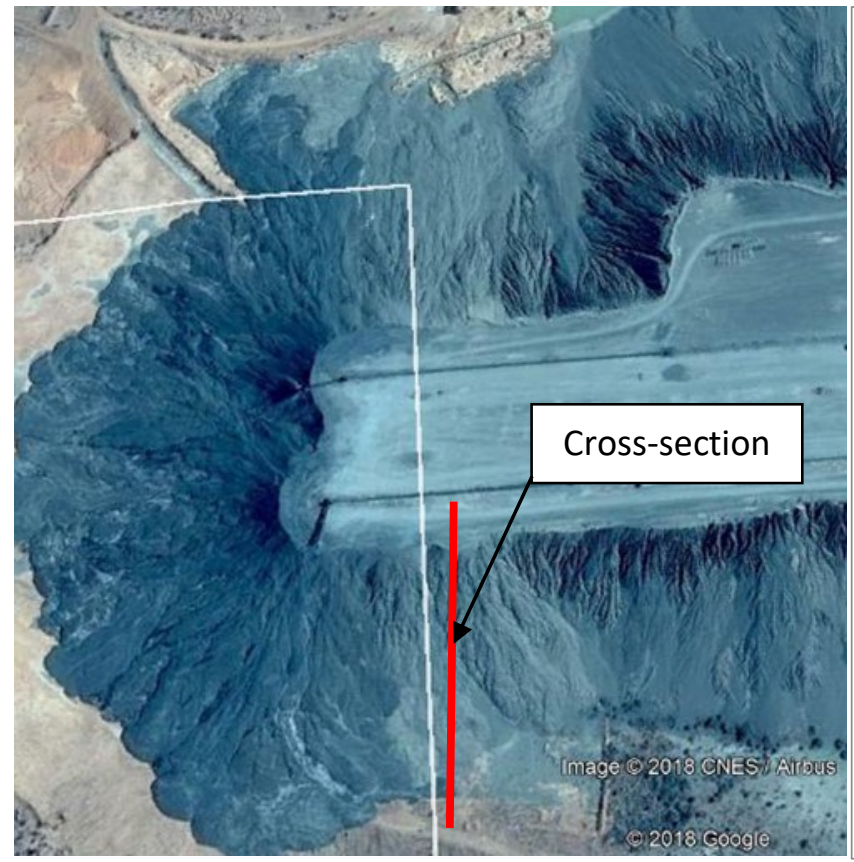

\section{Composite/Concave Slope Cross Section}

Figure 4 Google Earth image of a tailings dump that has a composite (concave) slope with appended cross-section 


\subsubsection{Dump advance rates}

The advance rate of the dump is a very important factor to consider. If the advance rate of the spreader is $50 \mathrm{~m} / \mathrm{mth}$, this requires frequent moves of the spreader, which could become impractical and require excessive use of the bypass stockpile facility. Similarly, at this advance rate the dump surface may not have consolidated adequately to support the weight of the advancing spreader and may settle or develop large cracks and affect the safety and stability of the advancing equipment. To reduce the advance rate, more spreaders are required with associated transfer towers and conveyor legs, which add to the costs and redundancy of the system.

A higher dump would have a lower advance rate than a lower dump. In some cases, a slow advance rate would result in a single steep dump slope, while a faster advance rate for the same material would result in a composite slope. Therefore, the advance rate is a critical design parameter as it impacts on the number of spreaders or dozing distances.

\subsubsection{Dump height}

Determining the dump height for design impacts the dump footprint and is also associated with closure criteria for the final slopes. Higher dumps may require more energy to lift the material, while a flatter dump will require longer conveyors, and only slightly less energy. Trade-off studies may be required to assess the best approach. Higher dumps are exposed to higher winds at the crest, which may impact on spreader stability. It is likely that a higher dump would be more unstable if moisture conditions vary considerably.

\subsubsection{Stormwater and seepage management}

For kimberlite or diamond tailings dumps, the groundwater impacts are generally low to nil as the ore or gravels are not geochemically active and the process typically involves crushing, washing and dense media separation. This coupled with the low moisture content at deposition means there is little need for seepage interception or lining for groundwater protection. However, consideration may need to be given to underdrainage in higher rainfall areas and where the foundation comprises clay or very shallow rock to reduce pore pressures and improve stability. Similarly, stormwater management on top of the dump is required to drain runoff away from the active face while controlling it so that it does not erode side slopes or the ramp through uncontrolled discharge. This is done by making the spreader system advance at a $1-2 \%$ incline, bearing in mind that dump settlement may reduce the dump height. If runoff is allowed to flow towards the active face, it could lead to instability and operational interruption as in this area the tailings is at it wettest, loosest and closest to operational equipment.

\subsection{Dump design and modelling}

\subsubsection{Dump modelling}

The tailings and grits production rates and site survey are essential to start some preliminary airspace modelling of sites and options, as shown in Figure 5. This approach will quickly determine the overall footprint, height and site layouts for life-of-mine. This is then used in selecting the preferred site and height (bearing in mind closure slope profiles). The number of conveyor legs and spreaders required to match the production rate must then be determined as shown in Figure 6 . It is common to have a starter ramp initially with one leg/spreader, but if two or more legs are required and the site has low topography, the design must consider how the dump will operate until the second leg is operational. The distance between multiple legs is typically based on the spreader length plus a $30 \mathrm{~m}$ lateral dozing distance, which is considered to be cost-effective. For a $25 \mathrm{~m}$ long spreader, the distance is then $110 \mathrm{~m}$ apart. The valley between the two legs is then filled by dozing. The distance apart may also be a function of the dump height, being closer if the height is less than $20-25 \mathrm{~m}$. 


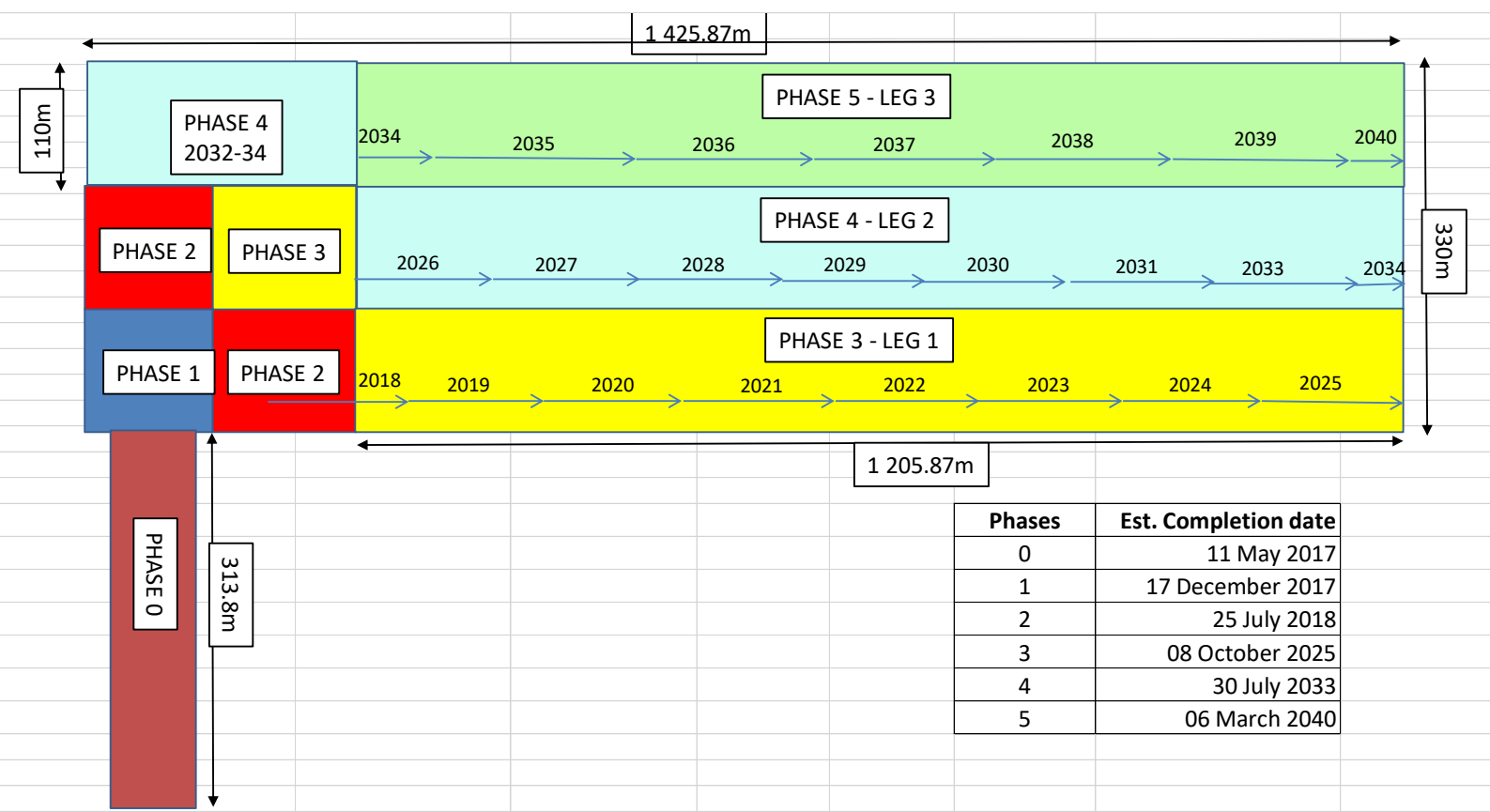

Figure 5 Preliminary modelling and phasing of dump, including starter ramp and multiple legs

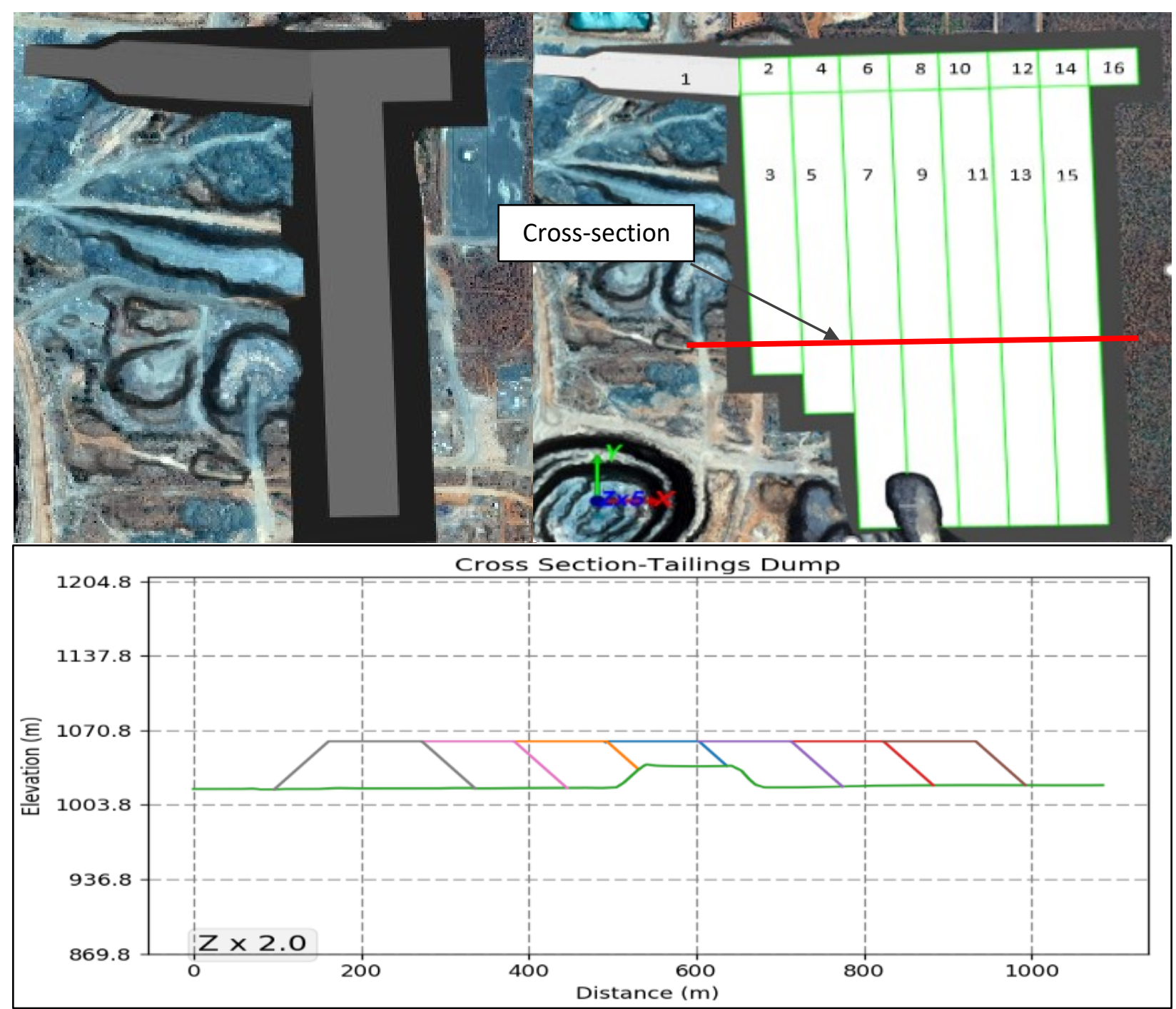

Figure 6 Detailed modelling showing zone numbering with appended cross-section through legs 
The dump modelling can often be an iterative process because the conveyor designers (and client) would need to determine spreader size, length, capacity (number of legs), all of which have capital cost implications. The dump height, slope angles and rate of advance remain key factors in this process. Once these have been agreed, then the dump development plan can be generated for monthly, quarterly and annual time steps. This plan determines the costs, both capital and operating costs, and when new transfer towers, conveyors and spreaders are required, the volume of trucking from bypass nodes, and dozing costs. The operational costs can be very sensitive to the time taken to advance a spreader. For example, if a spreader is advanced $30 \mathrm{~m}$ at a time, and this takes eight hours, then eight hours of tailings production must be dumped elsewhere (unless there are redundant legs to continue depositing on the dump).

\subsubsection{Starter works}

For a new dump, a starter ramp is required up onto which the initial conveyor and spreader system must advance as the tailings is deposited and then advances over the tailings. If an earth ramp height of $20 \mathrm{~m}$ is to be built initially, but the desired dump height is $40 \mathrm{~m}$, the conveyor and spreader system must continue up the ramp slope to this height, before levelling off. The ramp slope is often specified to be between 8 and $10^{\circ}$, based on vehicle access safety (including cranes), the ability of the conveyor system to drag itself up the slope, and the roll back angle of the material on the conveyor belt. It should be borne in mind that sections of the belt are at steeper angles than the ramp slope, where they rise up to a transfer tower or spreader. The maximum roll back slope for diamond tailings is probably between 15 and $20^{\circ}$, but depends on the belt speed, grading, moisture content and rain. The ramp is not an insignificant earthworks cost, as a crest width of $15-20 \mathrm{~m}$ is not uncommon to allow access on both sides for maintenance, stormwater drainage and dozing of tailings.

\subsubsection{Bypass facilities}

It is essential to include a bypass or emergency stockpile leg on the conveyor system, which can either be close to the base of the ramp or half way up the ramp. The stockpile will need to be sized for the time required for the spreader system to advance up the ramp or on top of the level dump. The stockpiled tailings would need to be removed immediately after that to allow space for any other conveyor stoppage in order to avoid stopping the plant. If removed by truck, the destination for the tailings might be at the toe of the advancing face, or tipped at the crest of the dump. The alternative is to have a reloading facility onto the conveyor, using a front-end loader and trough feed box that controls the rate at which the tailings loads the belt, so as not to overload it with each bucket.

Once a dump has been operating for a few years, an additional bypass node can be established on the dump to reduce the use of the bypass near the ramp and associated trucking/reloading costs.

\subsubsection{Adding additional legs and spreaders}

There are a number of spreader types that can be considered in the design stage, all of which typically have a swivel system for rotation, but the level of complexity depends on the type:

- Cantilevered spreaders, typically the most expensive.

- Boom spreaders that are supported on crawlers which can drag the spreader unit forward.

- Boom spreaders that are supported on wheels, either large tyres or resting on rails.

- Tripper mounted spreaders that work with face conveyor systems and travel parallel to the face, and often have the flexibility of being able to front and back stack by swivelling both sides of the conveyor, as shown in Figure 7. 


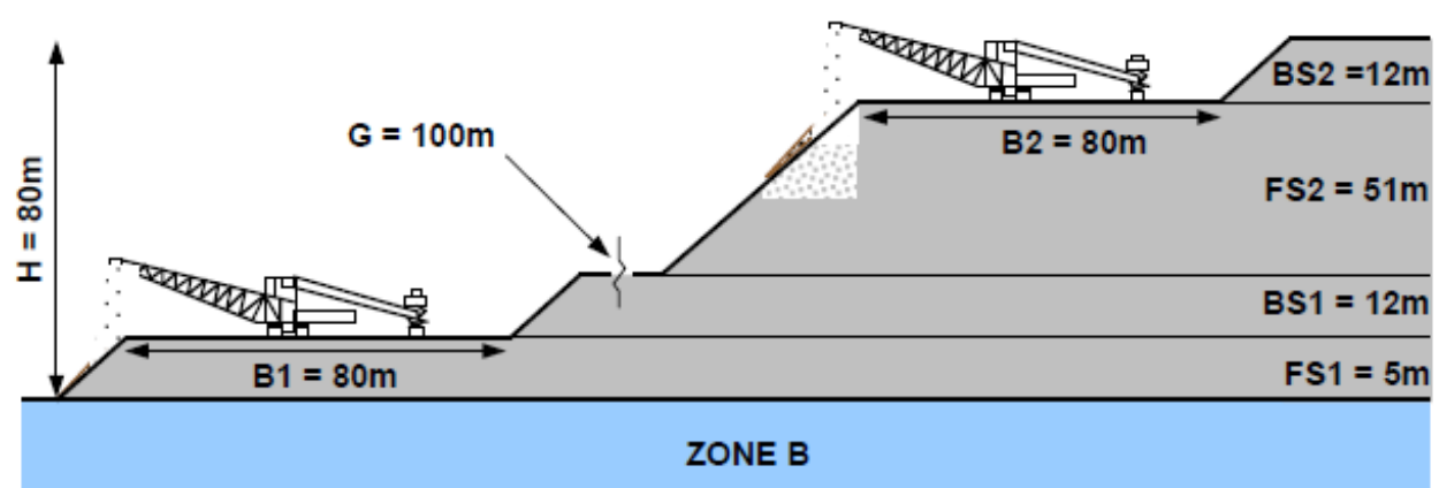

Figure 7 Section of a dump model showing the use of multiple face conveyors with front stacking (FS) and back stacking (BS)

The boom spreaders $(30-40 \mathrm{~m})$ are typically longer than the cantilever types $(20-25 \mathrm{~m})$, due to the supports mounted close to the face. The bearing pressures of the crawlers, tyres or rail mounted supports need to be considered as more settlement takes place close to the face. Ideally the spreader discharges tailings over the edge of the dump requiring minimal dozing, however it is common for piles to be formed at the face, and therefore a 5-6 m stacking height provides storage between each rotation of the spreader and for dozing of the tailings as far as $30 \mathrm{~m}$ to the face (i.e. prior to an advance of the spreader).

It is no simple process to add additional legs to a dump system during operation. This must be properly planned and executed. The dump needs to be advanced well beyond the position of a new transfer tower before construction commences, and once this point is reached, the bypass facility will have to be used for an extended time, requiring continual removal by truck. For a $25 \mathrm{~m}$ long spreader, plus a $40 \mathrm{~m}$ conveyor feed system with belt storage, this requires at least $70 \mathrm{~m}$ of dump to be established not only in the direction of advance, but also in the direction of the new leg. This necessitates extra dozing, more than normally required.

It is common for a transfer tower to be built with adjustable legs to accommodate settlement and differential settlement of the dump. Tower bases are prone to settle more if water can pond around them and both stormwater and spillage need to be managed accordingly. Steel spacer plates need to be added near the tower bases. The concrete bases need to be designed accordingly.

\subsubsection{Multiple legs versus face conveyors}

Face conveyors lend themselves to sites with steeper topography or where an existing dump/hill face allows them to be installed. Their advantages are that they are not moved frequently, resulting in fewer stoppages, and for large tonnages, only one spreader is required. However, when they are advanced, this takes longer than for normal spreaders and larger bypass nodes or stockpile areas are required.

There are principally two types of face conveyors, those mounted on crawlers that walk forward on tracks, and those mounted on sleepers and railway tracks as shown in Figure 8.

1. For the crawler mounted system, the suspended sections in-between the crawlers are essentially bridge structures that carry the full load of the tripper conveyor and spreader as it moves parallel to the face. This makes it a very heavy system and the motors that drive every crawler must be designed accordingly. If the crawler tracks sink into the tailings under the load, the motors must be strong enough to drive out. High flotation tracks may be required to reduce this risk.

2. For the sleeper and rail mounted system, the conveyor is made up of 3-6 m loosely connected sections that allow a dozer to drag them forward when the belt tensioning is released. By fitting an overhead pulley to lift the rail, and rail hitch to drag it forward, the dozer can walk parallel to the conveyor and slides it forward 0.5 to $1.0 \mathrm{~m}$ at a time on its sleepers. By repeating this action, a $25 \mathrm{~m}$ advance (or similar) can be achieved in a shift. At the start of the move the tripper/spreader 
is parked close to the transfer point while the rest of the conveyor is snaked forward. When the end of the conveyor is in position, the tripper must be driven there, while the near end is snaked forward. After this the transfer point must be advanced (as would be required for the crawler system). Before tensioning up the belt, minor adjustments are required to align and level the sleepers due to the dragging process.

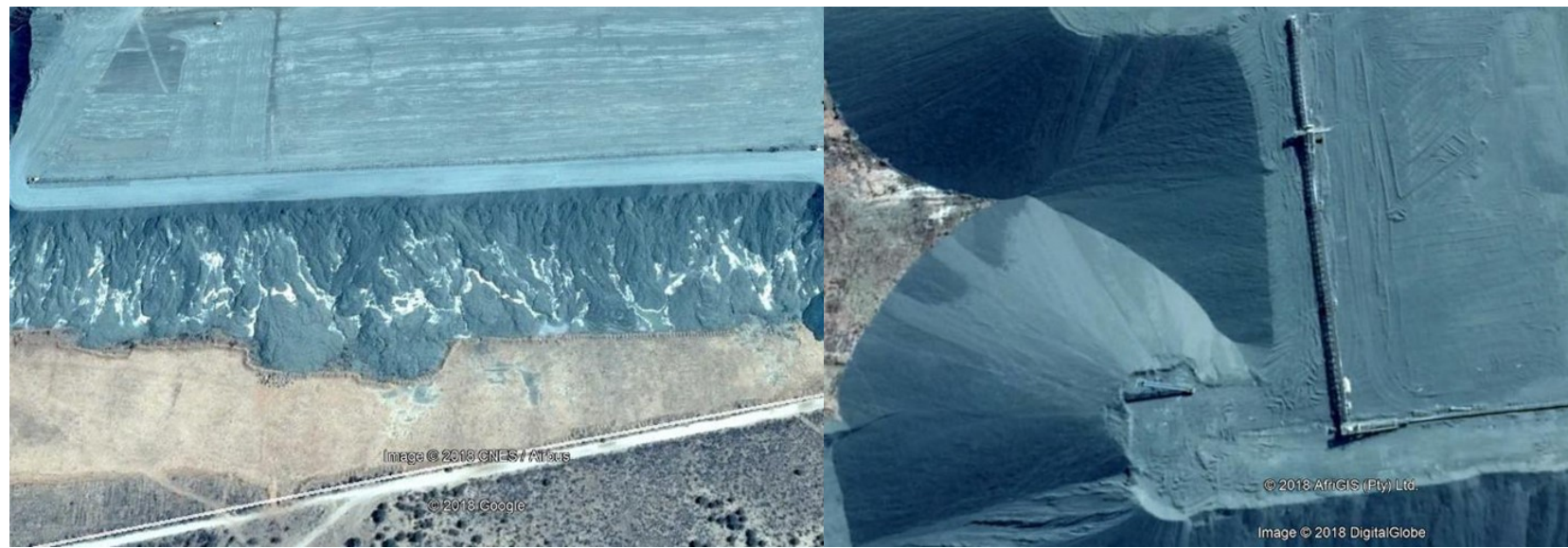

(a)

(b)

Figure 8 Google Earth images of tailings dumps: (a) With sleeper and rail mounted face conveyor system; (b) With crawler mounted face conveyor system

In both cases a prepared platform is required ahead of the conveyor to advance it. This not only ensures that the platform is at the right levels, but that the upper layers of tailings are nominally compacted to minimise settlements. The tripper and spreader machines are settlement sensitive and operate within tight tolerances, in addition to needing to withstand wind loading. It is important to operate a face conveyor in such a way that the end does not have to advance over freshly deposited tailings that have not consolidated adequately to carry the load of the machine. Face conveyors require anchors at the ends for tensioning of the conveyor belts, and these too need to be built into consolidated tailings.

If a steep, single slope dump is designed (coarse tailings only), it must be accepted that the Factor of Safety (FoS) of the slope FoS = 1 because it is standing at its angle of repose. Software analysis may even show FoS $<1$, especially if there is a possibility of a phreatic surface build-up at the base or down the freshly deposited face. Does this mean the dump is unstable?

For a tailings/grits co-disposal dump, with a composite slope, it is unlikely that software can accurately predict the shape of the composite slope, and it would probably be a block/wedge failure. The use of software would also show that the composite slope has a FoS $=1$ as it continues to slump to form this slope, and hence is in a state of marginal equilibrium. Does this mean that the dump is unstable?

For many mining companies that expect FoS $>1.5$ for safe tailings dam operations, the concept of a FoS $=1$ is seen as high risk. However, for decades, diamond tailings dumps have been operated safely on this basis and using the observational approach, rather than numerical analyses. If moisture contents are controlled, dump behaviour is more predictable. Where moisture contents vary, and sections of a dump hang-up and then slump and repeat this cycle, there is a risk of equipment damage and production impacts. Maintenance of dewatering screens is therefore crucial, and this can also affect the grading of the tailings/grits.

Obtaining shear strength properties for coarse tailings requires different test equipment than for fine tailings, such as large shear boxes. In addition, maintaining repeatable B-bar values for use in analyses is not easy. 


\subsection{Monitoring and operational procedures}

Historically not much effort has been put into detailed monitoring, but this has improved. Operating manuals are becoming more common and auditing is not limited to annual inspections by external consultants. The data that is required includes:

- Bi-annual survey of the dump to monitor face advance, individual leg advances, and slope angles.

- Production tonnages and moisture contents.

- Spreader moves, dozing distances and dozer availability.

- Settlement, slumping and crack monitoring as shown in Figure 9.

Other operational data that may be relevant includes conveyor availability, transfer chute issues and spillage problems.

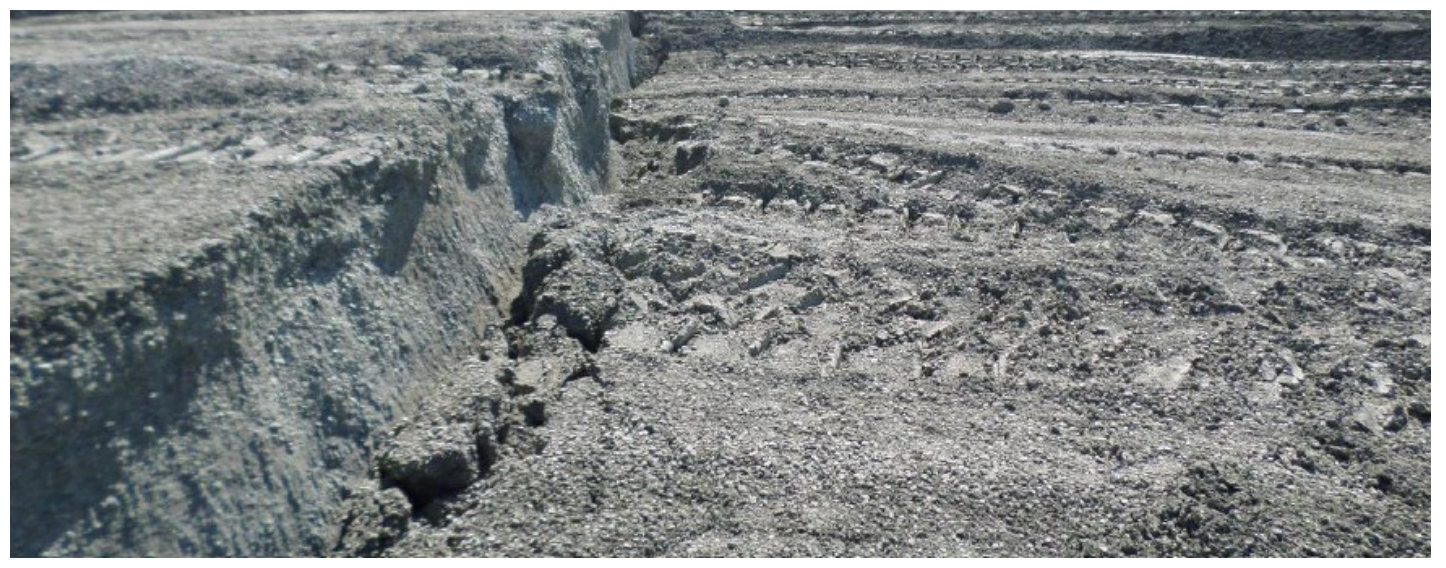

Figure 9 Photograph of a dump that has settled (failed) - tension crack formed

\section{$3 \quad$ Ash disposal}

\subsection{Types of ash and disposal methods}

Two main methods of dry stacking are used within the power industry, namely trucking/bulldozer, and the use of conveyors. Combinations of the two are also in use.

The material produced is made up principally of fly ash with a smaller percentage of coarser bottom ash, typically at an 80:20 split within South Africa. Fly ash leaves the boilers with the flue gases and is removed from these gases using electrostatic precipitators or other forms of filters such as bag filters. Bottom ash is too large to move with the flue gases and drops to the bottom of the boiler. Some power stations make use of flue gas desulphurisation process which also changes the properties of the fly ash with higher $\mathrm{CaO}, \mathrm{SO}_{3}$ and/or gypsum contents.

The percentage split of fly ash/bottom ash varies and the boilers of each power station are designed for a particular quality of coal. The calorific value, fouling agents, coal water contents, power station efficiencies as well the overall chemistry of the coal determine both the quantity/quality and the split of the ash produced. Certain types of boilers produce a large quantity of boiler slag which is not discussed within this paper.

\subsection{Key design parameters}

Fly ash and bottom ash have different geotechnical properties. Fly ash is predominantly silt sized while bottom ash is coarser with a larger sand fraction. The permeabilities reflect the difference in grain size. The internal angles of friction for fly ash are typically between $30-35^{\circ}$ with low to zero cohesion values. Laboratory test work is typical for geotechnical structures and tests may include Foundation indicator, 
triaxial testing, falling head permeability, shear box and compaction testing. Determination of the hydraulic conductivity function and volumetric water content functions can be useful depending on the design approach but are not typically used.

Fly ash does exhibit pozzolanic properties and hence its use in the cement industry. These pozzolanic properties, however, are not guaranteed within an ash deposit and ASTM Standard C618-84 (ASTM International 1984) suggests that the amounts of $\left(\mathrm{SiO}_{2}+\mathrm{Al}_{2} \mathrm{O}_{3}+\mathrm{Fe}_{2} \mathrm{O}_{3}\right)$ present must be greater than $70 \%$ by mass with loss of ignition (LOI) less than $6 \%$ and $\mathrm{SO}_{3}$ of less than $5 \%$ as stated in Blight \& Fourie (1999). Even with these conditions met, other factors such as free water, lime and sulphate availability determine whether pozzolanic hardening is likely (Blight \& Fourie 1999). Another process, carbonation hardening, can occur at the surface of ash deposits which gives good resistance against erosion but also requires certain conditions to be met (Blight \& Fourie 1999). Duvha power station, for example generates fly ash which does not gain these properties over time and has poor erosion resistance. Surface hardening is observed on dry ash deposits but the surface is easily broken once driven upon by trucks and/or light delivery vehicles (LDVs).

In a dry conveyed facility a certain amount of water is added for dust prevention, typically $15-30 \%$ by mass (Bhana et al. 1998). It was noted that on certain facilities with conveyed material the slope stacked at angles steeper than the angle of internal friction and therefore steeper than what was predicted using conventional effective stress strength parameters. The matric suction due to the low moisture contents was the reason for this additional strength gain. This strength would be lost following rainfall. This is due to a reduction in matric suctions as water contents increase. This drop in the slope stability FoS may endanger machinery on the crest.

Ash facilities within South Africa now require Class $C$ liner due to ash being classified as a Type 3 waste. This additional design consideration does mean that free drainage beneath the ash facility is not guaranteed and a shallow slip failure is possible. The addition of a liner also increases the complexity of stormwater management especially on sites with undulating terrain. The terrain may cause ponding on the liner often near an ash deposition face. This may cause slope failure due to wetting of the toe for a slope with an approximate FoS of 1 . On trucked facilities the trucks cannot and may not traverse over an uncovered liner. Soil protection layers are often thin due to financial considerations which in turn create the necessity of careful deposition planning and filling of ash. Bulldozers push ash over these soil protection layers with a specified minimum thickness to prevent damage from trucking, especially on turning circles.

Ash is fine and susceptible to wind. Dust prevention and dust suppression systems are required for any dry stacked ash facility. The addition of water also improves the likelihood of a hard crust forming, which is erosion resistant during storm events. Progressive rehabilitation on completed slopes is recommended and due to this the separation of clean and dirty water needs to be carefully planned.

It must be noted that older power stations designed for a particular coal quality may not receive this coal throughout its lifespan and within the context of South Africa's aging power stations the ash produced may increase in quantity and reduce in quality over time.

\subsection{Ash dump modelling}

Similar to tailings dumps, face conveyors are used, and the dump is built up in lifts, which requires a number of major relocations of the face conveyor system. These costs need to be considered in the trade-off study upfront. In the deposition plan design, stormwater needs to be directed to flow away from the active face to controlled areas, clean and dirty water separation, and the air space requirements and therefore deposition planning and modelling are similar to tailings dumps, as shown in Figure 10. Consideration should be given to progressive rehabilitation as early as possible. 


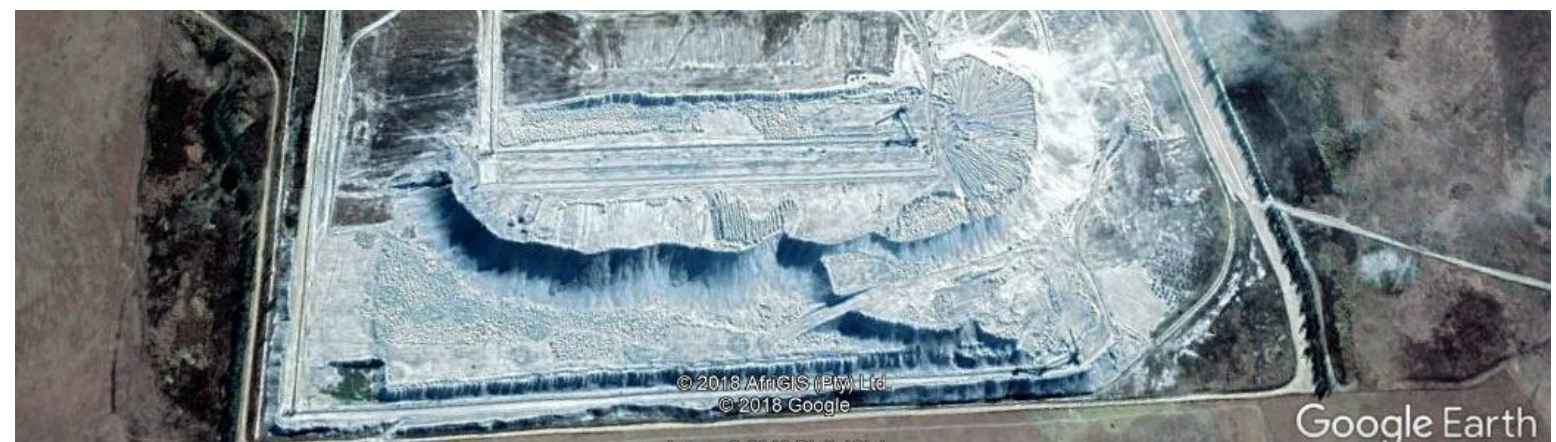

Figure 10 Google Image of ash dump with twin face conveyor system to form multiple lifts

Trucking of ash from a hopper (or stockpile) to the ash dump is another method commonly used with the power industry. It is different to that of conveyed material in that the ash is normally deposited in relatively thin layers and built up in localised zones as shown in Figure 11. The material is also subjected to compaction by either the movement of the trucks or compaction equipment such as smooth drum rollers. The ash does not compact particularly well but the addition of water for dust prevention at the hoppers and the dust suppression systems (irrigation) typically employed at these facilities does create a hard crust on the surface. Once this crust is formed it is best not to traverse over or break this crust with careful planning of haul routes as shown in Figure 12. Haul routes should be predetermined to reduce dust generation.
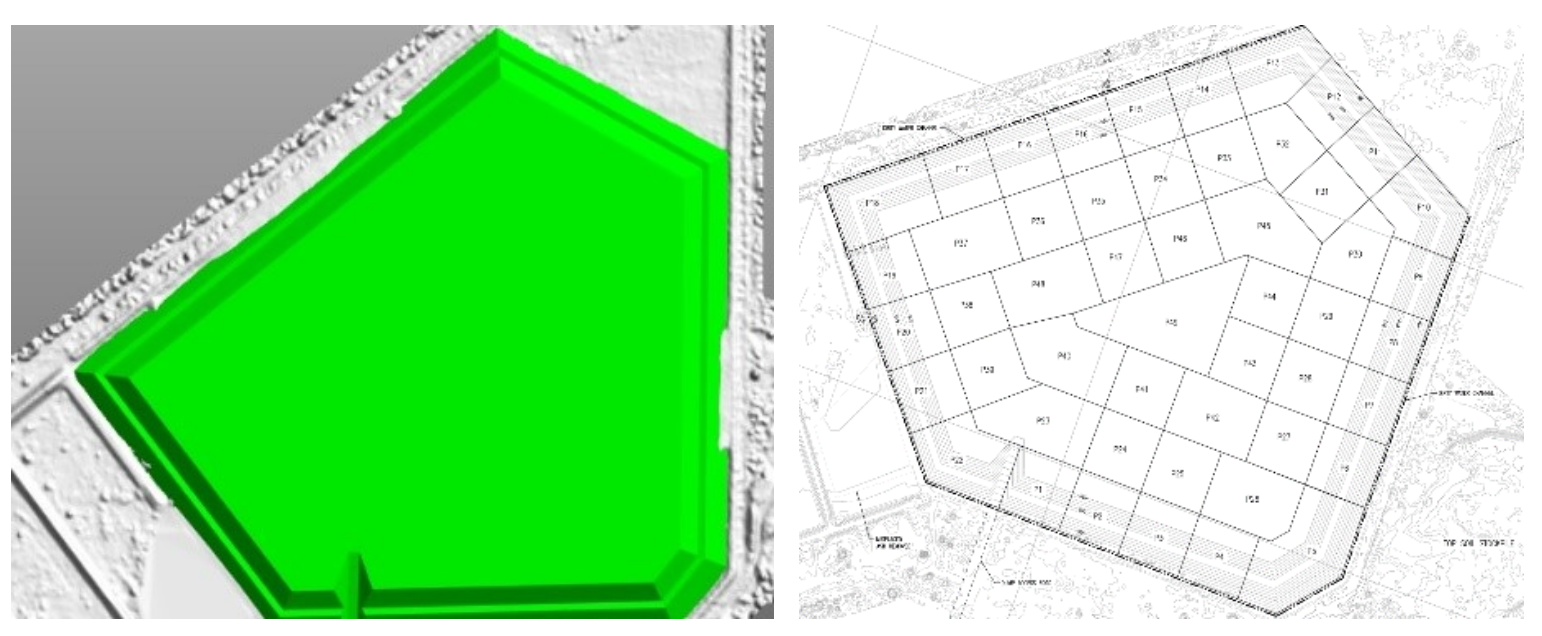

Figure 11 Trucked dry ash dump model and layout deposition plan

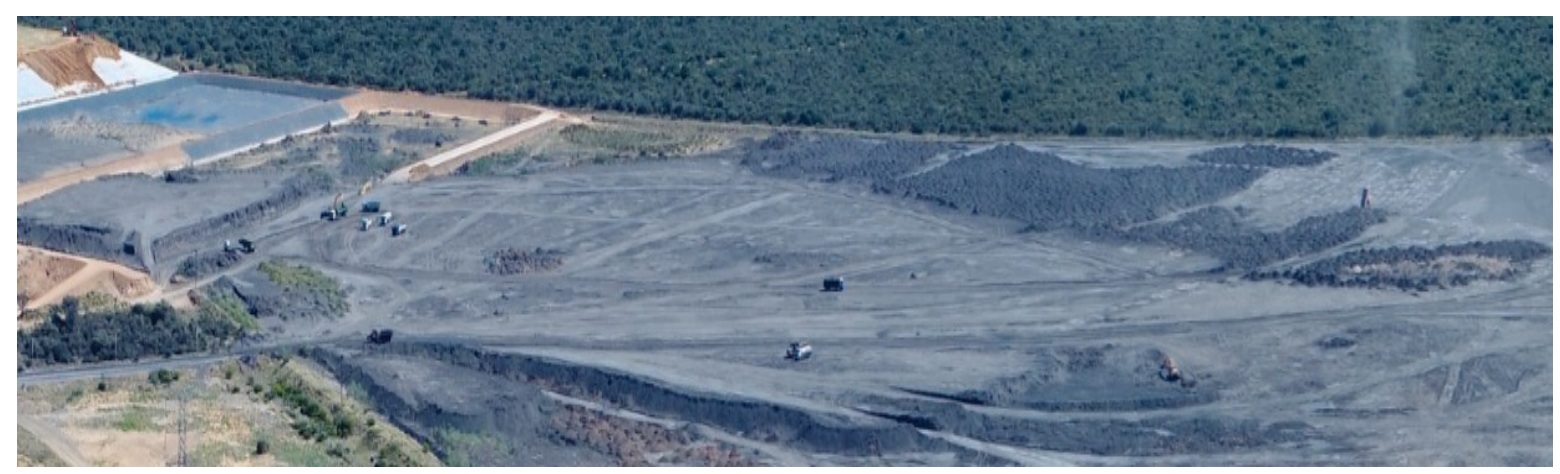

Figure 12 Load and haul dry ash operation using trucks and bulldozers

As with other load and haul operations cycle times of the trucks, numbers of trucks, sizes of trucks all need to be synced with the production rate, in this case the production of ash by the power station. The silo hopper size also needs to be optimised to fit into this production rate. Trucking also allows different ash 
types to be separated by class or geotechnical parameters and dry ash dumps should be planned with this in mind.

\subsection{Monitoring and operational issues}

To monitor and operate a dry ash dump certain criteria should be measured such as moisture content, slope angles, production rates, truck counts, LOI values and dust monitoring. Regular survey is important for planning and measurement of volumes against previous deposition plans and for stormwater management.

The surveys show areas which have been over deposited or under deposited which may create water drainage problems and correction of these through modelling and deposition planning is possible. If overly steep slopes have been formed these can be corrected with the next deposition stage or controls put in place to prevent equipment damage by settlement or slope failure. All this forms part of the observational method. The actual volumes deposited are also gathered from the survey. These volumes can then be compared to ash generation volumes which are often predicted with laboratory tests (under ideal conditions) and truck counts or conveyor weightometers. The deposition plan can then be updated against actual ash produced.

\section{$4 \quad$ Other factors to consider in the design of new dry stack facilities}

\subsection{Design similarities and differences}

The design of large filtered tailings dumps is slowly becoming more common, and to date only one significant facility exists in Southern Africa, namely the Skorpion Zinc tailings dump in Namibia. However, there are numerous diamond tailings and dry ash dumps in operation from which we should take as much learning as possible. The key differences between them are the moisture contents for filtered tailings, and the particle size gradings, which combined results in less stable dumps than can be achieved for ash and coarse diamond tailings. Therefore, a full range of test work on the fine tailings is required to understand its properties in the saturated and partially saturated condition. The side slopes of filtered tailings dumps depend on a number of factors, not least moisture content, but also dump height. Laboratory testing does not necessarily allow scale-up to field behaviour, and dump slopes is one area of uncertainty that must be considered in the design phase. The prediction of phreatic levels will depend on the dumping plan, liner or foundation materials, and management of stormwater on the dump surface and toe.

Some of the new filtered tailings dump designs include thin lifts and even compaction to improve stability, which will result in significant modelling differences and costs to the higher lifts common on ash and coarse tailings dumps. This changes the stacking equipment and possibly trucking requirements and is likely to be an iterative process to achieve an optimal design. Conveying of fine tailings is also a key design area to make sure the chute design copes with sticky materials and spillages, and when the filtered material is too wet, bypass stockpiles are essential. Similarly trucking of materials that hang-up in the truck bowls can be a risk and needs to be well understood upfront.

\subsection{Observational approach}

The observational approach has been employed successfully at a number of mine sites in the control of slope movements on dumps. Of the two cases described herein, the observational approach was effective in only one case.

\subsubsection{Case 1}

On a steep faced, single sloped dump with a height of $50 \mathrm{~m}$, a slump occurred on one of the three operational legs. Since there were two other legs it was decided that these could be used to allow the third leg to rest and consolidate. The third leg would then be used intermittently, and the fresh tailings would be 
dozed over the edge and the spreader would not be advanced. The idea was that the bulge that had formed would act as a buttress, and the dump could in time be continued as a steep sided dump. Due to some local ponding of rainfall runoff at the toe, which affected toe stability, this took longer than planned to be achieved, but did in time work, and the dump continues to operate as it did originally.

\subsubsection{Case 2}

On a steep faced, single sloped dump with a height of $70 \mathrm{~m}$, the mine decided to add grits to the coarse tailings. The grits tonnage added was relatively small and varied depending on plant operation. However, the moisture content varied significantly, and some chute blockages resulted with the addition of water. After about one year of operation the dump slumped, and within a short space of time, all four legs had slumped. Using the observational approach, the initial action was to control the moisture content and modify the chutes. It was also advised that complete removal of the grits would have been a better option. Again, the approach was to try to allow the dump to stabilise and use the slumped zone to self-buttress the dump. Three years later, and the dump is still slumping and the spreader equipment has not advanced much. The dozing distances are large and a waste rock buttress has been designed to arrest the slumping and allow the equipment to advance across what has been a permanent crack and settlement zone. In this case, the addition of grits was a significant change in operation, and the instability could not be reversed.

\section{Conclusion}

Previous experience gained within the diamond and power generation industry's dry stacked facilities give valuable information on how to go about design and operation of any dry stacked facility. The planning required for stormwater management, air space requirements, deposition planning and the machinery requirements are all important design aspects that can easily be applied to filtered tailings. Slopes and their sensitivity to moisture content will be more critical for finely ground tailings materials. It is important to understand failure mechanisms during the design process to enable the observational methods used during operation to allow designers and operators to adapt to challenges and variables. On dry stacked facilities which have large lift heights and steep slopes, it needs to be understood that the slope will have shallow slip failures since by its very nature the material stacks at a FoS near 1 . The machinery used for deposition must therefore be kept far enough away from the slope crest to prevent settlement and slip/block failure issues affecting equipment operation.

\section{References}

Alphabet Inc. 2019, Google Earth Pro, version 7.3.2.5491, computer software, Alphabet Inc., Mountain View California, viewed 20 February 2019, https://www.google.com/earth/

ASTM International 1984, ASTM C618-84: Standard Specification for Coal Fly Ash and Raw or Calcined Natural Pozzolan for Use in Concrete, ASTM International, West Conshohocken.

Bhana, Y, Fourie, A \& Blight, G 1998, 'The contribution of matric suction to the stability of an ash dump', Proceedings of Second International Conference on Unsaturated Soils, International Academic Publishers, Beijing, pp. 225-230.

Blight, G \& Fourie, A 1999, 'Erosion-resistant crusting of slopes of fly ash dam', Proceedings of the Sixth International Conference on Tailings and Mine Waste, A.A. Balkema, Rotterdam, pp. 189-195. 